\title{
PENYULUHAN PENGARUH MEDIA SOSIAL DI KALANGAN PELAJAR SEKOLAH MENENGAH ATAS CENDERAWASIH 1 JAKARTA
}

\author{
Fransiska Novita Eleanora ${ }^{1)}$, Andang Sari ${ }^{2)}$ \\ 1, 2)Ilmu Hukum, Fakultas Hukum, Universitas Bhayangkara Jakarta Raya \\ Email : fransiska.novita@dsn.ubharajaya.ac.id, andangsari29@yahoo.co.id
}

\begin{abstract}
ABSTRAK
Kegiatan pengabdian terhadap masyarakat yang dilaksanakan di Sekolah Menengah Atas (SMA) Cenderawasih 1 kota Jakarta berupa penyuluhan tentang media sosial yang semakin marak di gunakan khususnya terhadap penggunaannya dan pengaruhnya di kalangan pelajar baik yang positif dan juga negatif. Pengabdian ini bertujuan untuk memberikan pemahaman mengenai dampak dan juga akibat dari penggunaan media sosial, sehingga dalam menggunakannya dilakukan secara hati-hati, dan teliti serta cermat dan bijaksana supaya terhindar dari perbuatan yang negatif seperti melanggar terhadap kesusilaan, perjudian, penghinaan dan nama yang baik tercemar, pemerasan dan atau pengancaman, serta penyebaran berita yang bohong yang dianggap menyesatkan yang mengakibatkan adanya kerugian konsumen dan permusuhan antar individu disebarkan dan atau masyarakat yang tertentu dilihat dari kelompoknya beradasarkan suku, agama, ras, dan antar golongan (SARA)
\end{abstract}

Kata kunci : Media Sosial, Penggunaan, Pengaruh, Kalangan, Pelajar

\section{ABSTRACT}

Community service activities carried out in the Cenderawasih 1 high school in Jakarta in the form of counseling about social media which is increasingly widespread in use especially for its use and its influence among students both positive and negative. This service aims to provide an understanding of the impact and also the consequences of the use of social media, so that in using it is done carefully, carefully and carefully and wisely so as to avoid negative actions such as violating decency, gambling, insults and or defamation, extortion and or threatening, as well as spreading false news and deemed misleading resulting in consumer losses and spreading hatred or individual hostility and or certain groups of people based on ethnicity, religion, race, and intergroup (SARA)

Key words : Social Media, Usage, Influence, Circle, Students

\section{PENDAHULUAN}

Indonesia kini mengalami perkembangan yang sangat pesat di dalam bidang yang berkaitan dengan teknologi dan juga informasi dan berbagai komunikasi yang dimulai dari adanya tahun 2000 dan sampai sekarang ini. Teknologi yang baru dan banyak muncul dan dapat juga diterima oleh kebanyakan dari masyarakat di Indonesia. Dimana dalam tahun 2016 ada sebanyak 132,7 juta dari masyarakat Indonesia telah terhubung atau berkaitan denganadanya internet dan juga selalu terus bertambah dari setiap tahunnya. Trend yang ada ini menunjukkan bahwa dengan meningkatnya teknologi dalam jaringan internet dapatvdigunakan untuk seluruh kalangan dalam berbagai kehidupan untuk 
bersosialisasi dan berbisnis, baik yang berasal dari kalangan terhadap pelajar, juga mahasiswa, dan karyawan, maupun orang dewasa. Pemanfaatan yang demikian mengakibatkan teknologi terhadap informasi yang ada di samping memberi manfaat yang baik di kalangan pelajar di Sekolah Menengah Cenderawasih 1 Jakarta, juga di sisi lainnya memiliki kesempatan dan juga peluang untuk terjadinya penyalahgunaan dalam melakukan tindakan berbagai kejahatan baik yang biasa maupun yang secara khusus dan dapat mentargetkan adanya infrastruktur informasi dan juga teknologi dan juga komunikasi, serta dengan adanya dampak yang negatif dan dapat berimbas terhadap sistem dan tatanan yang sosial yang runtuh dan perekonomian dari Negara yang lumpuh, lemahnya sistim pertahanan serta dapat juga digunakan sebagai alat teror. Pengaruh dari media sosial yang berdampak positif memberikan manfaat yang baik bagi seluruh lapisan dari masyarakat dan juga kalangan pelajar dimana dengan adanya kecanggihan teknologi ini dampak atau pengaruh positif, diantaranya adalah sebagai media dalam penyimpanan informasi, situs dan jaringan sosial yang membuat anak-anak lebih bersahabat, akrab dan saling mengenal satu lainnya, dan mendapatkan informasi secara cepat dan mudah, serta mempertemukan saudara atau kerabat yang jah, bahkan dapat mempererat tali silahturahmi atau kekeluargaan dan mempermudah belanja online atau daring

Selain dampak yang positif seperti disebutkan di atas maka ada juga dampak yang negatif yang dapat ditimbulkan dari media sosial ini ada 6 (enam) aturan dalam undangundang ini yang perlu diketahui agar cermat dan selalu bermanfaat dalam menggunakan media sosial, yaitu dapat memiliki muatan yang melanggar kesusilaan, perjudian, penghinaan, atau nama yang baik dapat tercemar, terjadinya pengancaman dan pemerasan, penyebaran akan adanya suatu berita yang tidak benar dan juga menyesatkan hingga mengakibatkan adanya atau timbulnya kerugian terhadap konsumen. Dan adanya aturan hukum yang mengaturnya. Pemahaman yang baik di kalangan pelajar khususnya para dalam menggunakan medial sosial harus selalu teliti, hati-hati dan cermat serta bijaksana dalam menggunakan dan mengetahui dampak yang negatif sehingga tidak terjerumus ke dalamnya beserta dengan sanksi atau hukumannya yang diberikan sesuai dengan undang-undang yang mengaturnya.

Dikarenakan tujuan dari dibentuknya atau pembentukan dari Undang-Undang Informasi dan Transaksi Elektronik tercermin dari pasal 4: mencerdaskan segala kehidupan dari setiap bangsa dan merupakan sebagai bagian dari masyarakat dunia, mengembangkan adanya perdagangan dan juga perekonomian nasional dalam rangka kesejahteraan dari masyarakat yang meningkat; dan meningkatkan efektifitas dan pelayanan publik; juga membuka adanya kesempatan yang seluas-luasnya kepada setiap orang untuk selalu dapat memajukan akan suatu pemikiran dan juga kemampuannya di bidang akan penggunaan dan juga pemanfaatan terhadap teknologi dan informasi yang seoptimal mungkin dan juga selalu bertanggung jawab; dan selalu dapat memberikan akan adanya rasa aman, dan keadilan, dan juga kepastian akan hukum bagi setiap pengguna dan penyelenggara terhadap teknologi dan informasi yang ada.

\section{TINJAUAN PUSTAKA}

Istilah dari Media dan Sosial diartikan sebagai alat dari komunikasi (Laughey, 2007; McQuail, 2003). Sedangkan kata sosial diaertikan sebagai kenyataan yang sosial bahwa setiap individu melakukan aksi yang memberikan kontribusi kepada masyarakat, sehingga media sosial adalah alat komunikasi yang digunakan oleh pengguna dalam proses interaksi dan sosial. Penyusunan dari media sosial perlu dilihat perkembangan dari hubungan antar individu yang ada dengan berbagai perangkat dari media, yaitu 
karakteristik dalam kerja akan komputer yang ada dalam Web 1.0 berdasarkan pengenalan terhadap individu terhadap kepada individu yang lain (human cognition) dan berada dalam sebuah sistem jaringan, sedangkan Web 2.0 berdasarkan sebagaimana individu berkomunikasi (human communication) dalam jaringan adanya antar individu. Sedangkan dalam Web 3.0 adanya karakteristik akan teknologi dan juga relasi yang terjadi sudah terlihat dari bagaimana manusia (users) bekerja sama (human cooperation) (Fuchs, 2008).

Keberadaan media sosial yang pada dasarnya merupakan bentuk yang tidak jauh berbeda dengan keberadaan keja dari komputer. 3 (tiga) bentuk bersosial seperti pengenalan, dan komunikasi dan kerja sama dapat dianalogikan atau dipersamakan dengan cara kerja dari komputer yang dapat membentuk adanya sistem yang ada antara masyarakat dengan individu (Nasrullah, 2015).

\section{METODE PELAKSANAAN}

Kegiatan ini dilaksanakan oleh TIM dari Fakultas Hukum Universitas Bhayangkara Jakarta Raya serta diikuti oleh 39 (tiga puluh sembilan) siswa SMA Cendrawasih I Jakarta Selatan. Sebelum acara dimulai, panitian membagikan dan mengisi form kepada peserta mengenai identitas diri. Keterlibatan mahasiswa di sini ingin menjelaskan kepada para peserta pentingnya memahami Undang-Undang ITE agar dalam penggunaan akan media sosial tidak melanggar kesusilaan, melakukan pencemaran nama baik, tidak menyebarkan akan berita yang bersifat bohong dan juga menyesatkan yang dapat mengakibatkan adanya kerugian orang banyak, menyebarkan ujaran kebencian atau permusuhan terhadap individu atau juga berbagai kelompok dari masyarakat tertentu yang ada berdasarkan akan SARA.

Dalam melaksanakan kegiatan pengabdian masyarakat ini berupa penyuluhan hukum ini dilakukan langkah-langkah yaitu ;

(1) Pembukaan sekaligus dengan perkenalan

(2) Presentasi atau pemaparan dengan memaparkan materi yang terkait dengan penyuluhan tersebut.

(3) Pembagian pretes dan postes sebelum dan sesudah kegiatan pengabdian dimulai

(4) Sesi tanya jawab, di mana para peserta (siswa dan para guru) bertanya mengenai apa pentingnya UU ITE khususnya dalam penggunaan dari media sosial yang baik di kalangan siswa sekolah maupun masyarakat luas pada umumnya.

\section{HASIL DAN PEMBAHASAN}

Hasil

Tabel 1. Hasil Pretes dan Postes

\begin{tabular}{|c|c|c|}
\hline Unsur & Pra Pengabdian & Pasca Pengabdian \\
\hline $\begin{array}{l}\text { Hukum } \\
\text { aturan }\end{array}$ & $\begin{array}{l}\text { belum memahami aturan } \\
\text { mengenai Informasi dan juga } \\
\text { Transaksi Elektronik }\end{array}$ & $\begin{array}{l}\text { sudah lebih memahami aturan } \\
\text { mengenai Informasi dan juga } \\
\text { Transaksi Elektronik }\end{array}$ \\
\hline $\begin{array}{l}\text { Pengaruh Media } \\
\text { Sosial }\end{array}$ & $\begin{array}{l}\text { belum memahami mengenai } \\
\text { pengaruh yang negatif }\end{array}$ & $\begin{array}{l}\text { sudah lebih memahami adanya } \\
\text { pengaruh yang negatif }\end{array}$ \\
\hline
\end{tabular}




\section{Pembahasan}

Hasil di atas menunjukkan sebelum atau pra pengabdian tidak mengetahui dan tidak / belum memahami mengenai aturan tentang ketentuan informasi dan juga transaksi dari elektronik, dan tidak mengetahui pula bahwa aturan-aturan mengenai tersebut sangat penting diketahui oleh pelajar pengguna media social, bukan itu saja pengaruh dari media sosial yang beedampak yang negatif yang tercantum dalam pasal 45 tersebut Setelah pasca pengabdian sudah lebih memahami mengenai aturan hukum dan pengaruh atau dampak negatif dari penggunaan media sosial

Adapun ketentuan tersebut yang memang berlaku untuk dan bagi setiap orang yang sudah melakukan adanya suatu perbuatan hukum sebagaimana telah diatur dalam ketentuan dari undang-undang mengakibatkan kerugian bagi kepentingan orang banyak, dengan demikian dalam penggunaan media sosial di kalngan pelajar harus lebih cermat dan teliti serta hati-hati dan bijaksana dalam menggunakannya dan mengaksesnya supaya tidak terjerat dalam kasus atau tindak pidana yang ada.

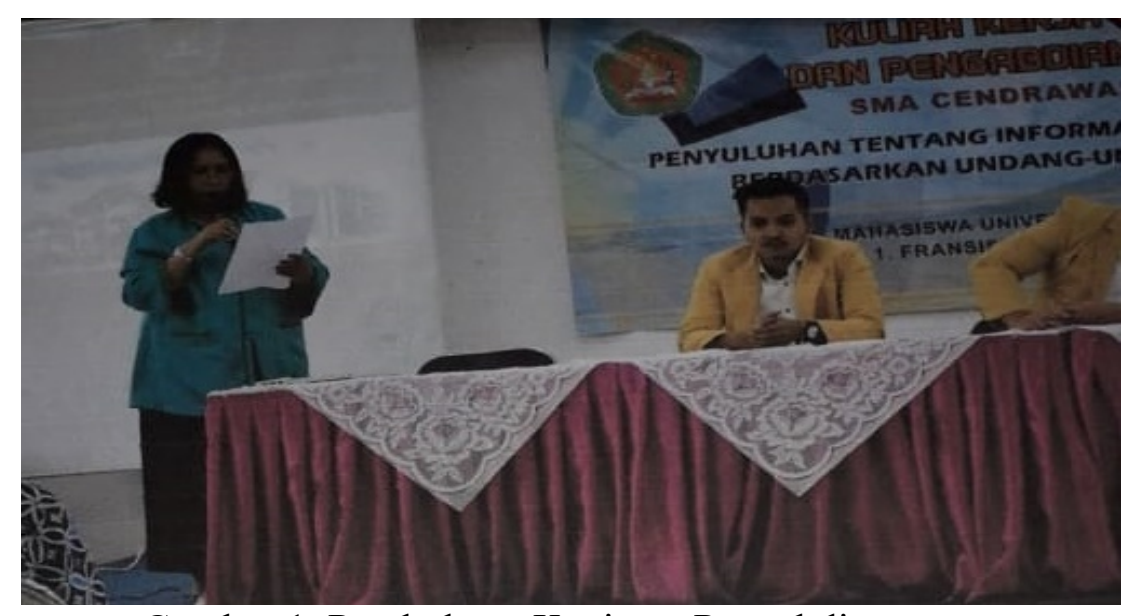

Gambar 1. Pembukaan Kegiatan Pengabdian

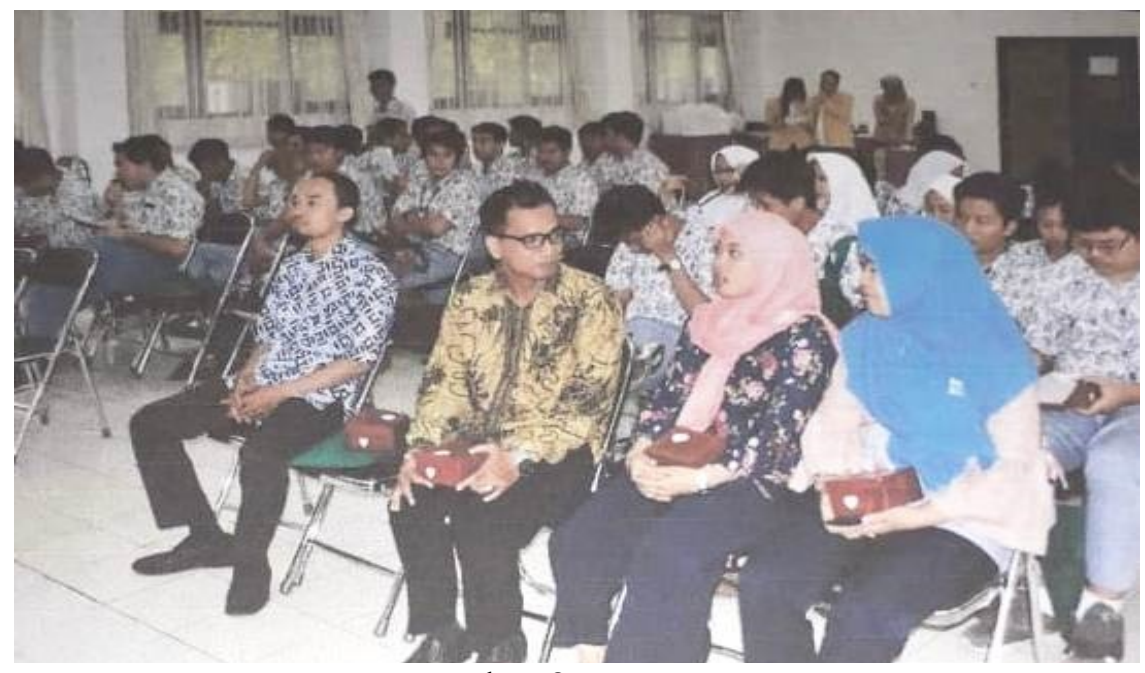

Gambar 2. Peserta 


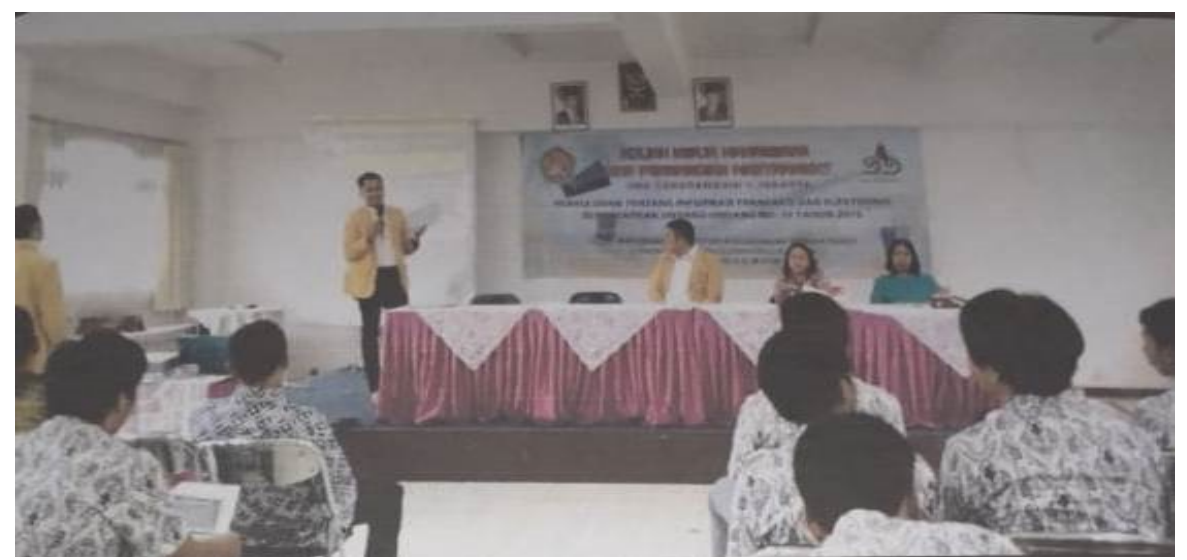

Gambar 3. Kegiatan Penyuluhan

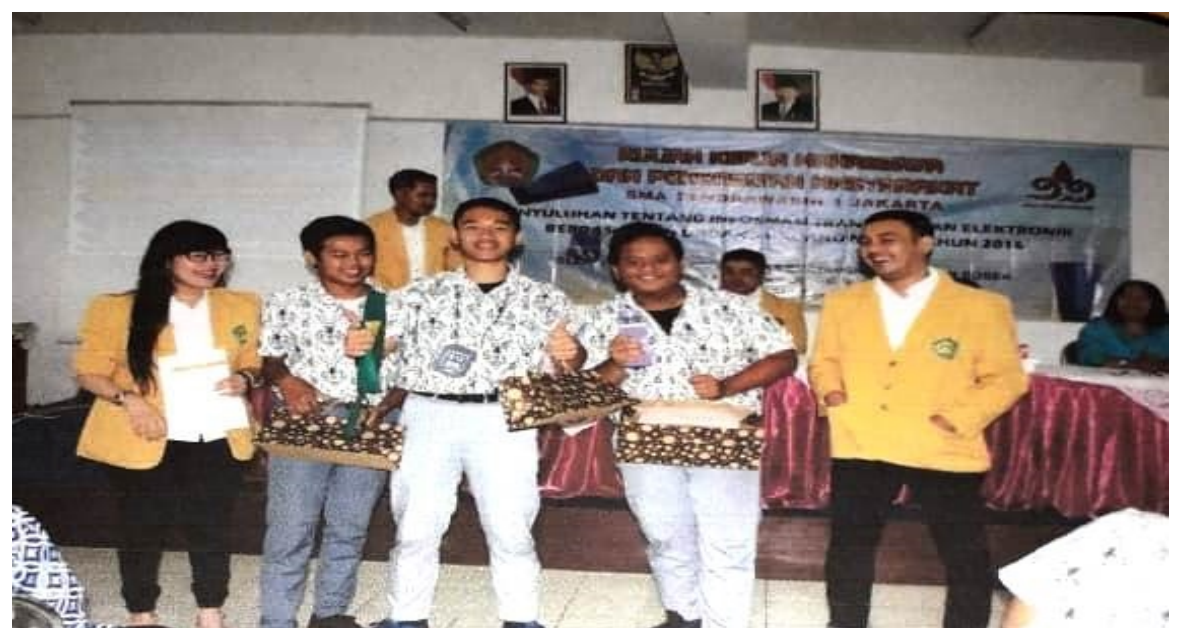

Gambar 4. Siswa yang aktif memberikan pertanyaan

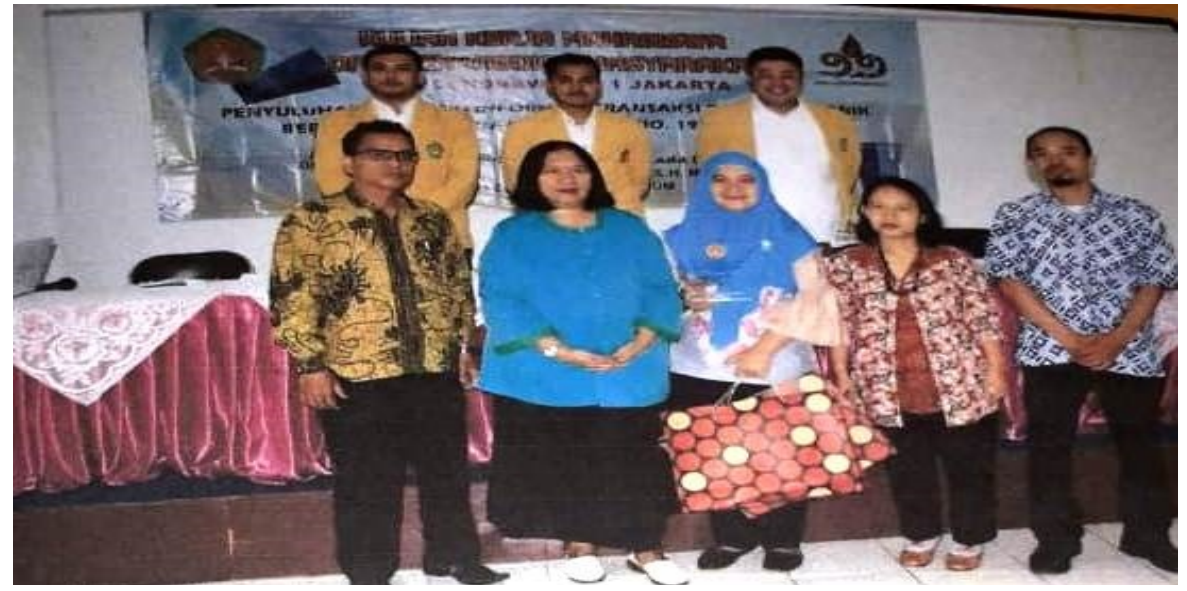

Gambar 5. Peserta Guru pendamping 


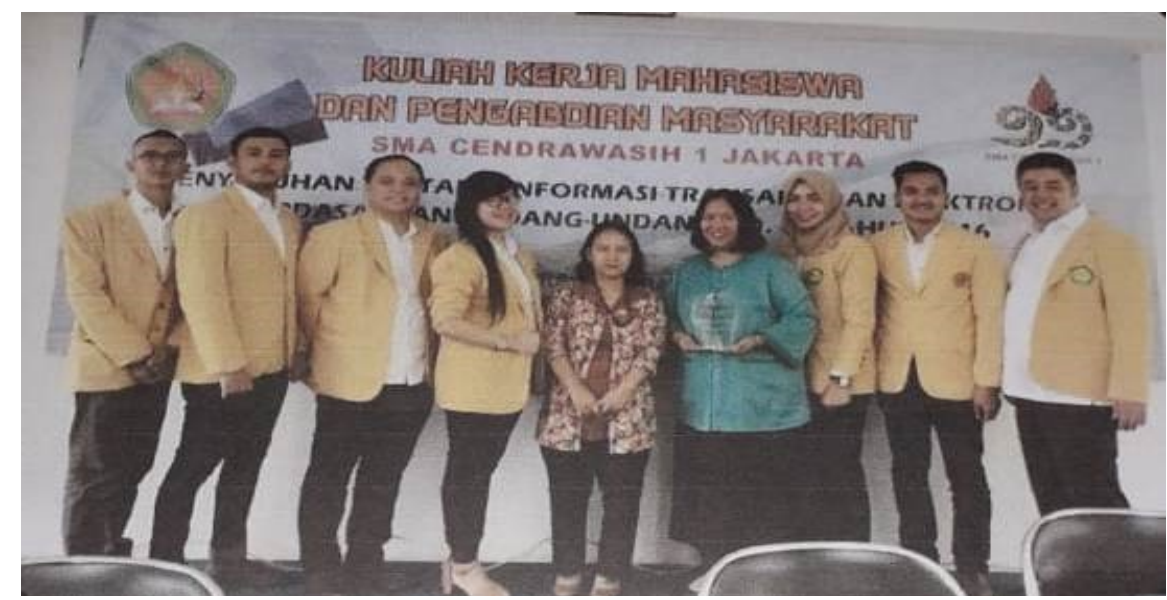

Gambar 6. TIM Pelaksana Pengabdian

\section{KESIMPULAN}

Media sosial di kalangan pelajar penggunaannya memberikan dampak dan pengaruh yang positif dan negatif, dimana selain memberikan ilmu pengetahuan, juga wawasan dan informasi maka ada dampak negatif yang harus dihindari dari penggunaan media sosial, seperti dapat memiliki muatan yang melanggar kesusilaan, perjudian, penghinaan, atau pencemaran akan nama baiknya seseorang, pemerasan dan atau terjadinya pengancaman, bahkan penyebaran dari berita tidak benar dan menyesatkan sehingga dapat juga mengakibatkan kerugian konsumen. Agar tidak melanggar ketentuan tersebut maka pelajar harus selain bijaksana, teliti dan cermat dalam penggunaan akan media sosial yang ada juga harus memahami aturan hukum yang ada yaitu ketentuan peraturan tentang Informasi dan juga Transaksi Elektronik dengan Nomor 19 Tahun 2016.

Terima kasih kepada Wakil Kepala Sekolah Bidang Kurikulum Sekolah Menengah Cenderawasih 1 Jakarta yang telah membantu dan mepermudah team dalam melaksanakan kegiatan dalam pengabdian ini sehingga dapat berjalan dengan baik dan lancar

\section{DAFTAR PUSTAKA}

[1]. Fuchs, C. 2008. Internet and society, social theory in the information age. Madison Ave, NY: Roudledge.

[2]. Laughey, D. 2007. Themes in media theory. New York: Open University Press.

[3]. McQuail, D. 2003. Teori komunikasi massa. Jakarta: Penerbit Erlangga.

[4]. Mulawarman, \& Dyas, N. A. 2017. Perilaku Pengguna Media Sosial Beserta Implikasinya Ditinjau dari Perspektif Psikologi Sosial Terapan, Buletin Psikologi, DOI: 10.22146/buletinpsikologi.22759, 25 (1), 36-44

[5]. Nasrullah, R. 2015. Media sosial (perspektif komunikasi, budaya, dan sosioteknologi). Jakarta: Simbiosa Rekatama Media 